\title{
Belleza plástica, eugenesia y educación física en Chile: presentación de la fuente "Aspectos de la educación física", de Luis Bisquertt (1930)
}

\author{
Plastic beauty, eugenics and physical education in Chile: \\ a commentary on the work "Characteristics of physical \\ education", by Luis Bisquertt (1930)
}

\section{Enrique Riobó ${ }^{i}$}

'Coordinador, Red Historia de las Universidades Chilenas/Archivo Central Andrés Bello.

Santiago - Chile

orcid.org/0000-0003-3702-0155

enrique.riobo@gmail.com

\section{Francisco Javier Villarroel $^{i}$}

i Coordinador de línea, Universidad y Deporte, Red Historia de las Universidades Chilenas/Archivo Central Andrés Bello. Santiago - Chile orcid.org/0000-0001-5482-5671 fvillarroel21@gmail.com

Recebido em 21 abr. 2017. Aprovado em 20 mar. 2018
RIOBÓ, Enrique; JAVIER VILLARROEL, Francisco. Belleza plástica, eugenesia y educación física en Chile: presentación de la fuente "Aspectos de la educación física", de Luis Bisquertt (1930). História, Ciências, Saúde Manguinhos, Rio de Janeiro, v.26, n.2, abr.-jun. 2019, p.673-693.

Resumen

El siguiente texto busca presentar y contextualizar la fuente "Aspectos de la educación física", de Luis Bisquertt, poniendo énfasis en la búsqueda del mejoramiento racial en Chile de 1930, a partir de la educación física eugénica, cuyo paradigma corporal serían las estatuas clásicas helénicas. Uno de los conceptos centrales de este documento es el de belleza plástica, cuyo sentido se encuentra totalmente imbricado a la idea de normalidad y sanidad, patologizando aquellos cuerpos que no se enmarquen en el canon atlético, situación extendida por las características sedentarias de la modernidad.

Palabras clave: educación física; eugenesia; belleza plástica; Grecia clásica; Luis Bisquertt Susante (1895-1970).

\section{Abstract}

The article seeks to introduce and contextualize the work "Characteristics of physical education" ("Aspectos de la educación fisica"), by Luis Bisquertt, which emphasizes the effort to ameliorate racial aspects in Chile, in 1930, thru physical education eugenics, whose body paradigm were the Hellenic classical statues. One of the key concepts of this document is plastic beauty, whose meaning overlaps with the idea of normality and sanity, creating pathologies on those bodies that were considered outside of the athletic standards, a situation that was aggravated by the sedentary conditions of modern times.

Keywords: physical education; eugenics; plastic beauty; classic Greece; Luis Bisquertt Susarte (1895-1970). 


\section{Nacionalismo, eugenesia y actividad física (1870-1942)}

La búsqueda por definir lo nacional es central dentro de las discusiones públicas de la primera mitad del siglo XX latinoamericano, contexto donde las perspectivas raciales y eugénicas tenían importantes grados de hegemonía. Estas disputas por delimitar aquello que se comprenderá por "lo nacional" son parte de los procesos de crisis oligárquicas, que se estarán incubando desde finales del siglo XIX, pero que explotan con la Revolución Mexicana en adelante (Mariátegui, 1924; Subercaseaux, 2011). En el caso chileno, este proceso comienza con las discusiones sobre el centenario (Correa et al., 2008), y políticamente llega a un punto cúlmine en la década de 1920, con la elección de Arturo Alessandri primero; luego con su salida y posterior dictadura de Ibáñez del Campo; y finalmente con una seguidilla de gobiernos militares y civiles que terminarán con la vuelta de Arturo Alessandri al poder en 1932.

En este contexto, la concepción sobre lo nacional se hizo crecientemente inseparable de perspectivas primero higiénicas y luego eugénicas (Leyton, Palácios, Sánchez, 2015), las que tenían un componente de género muy marcado (Subercaseaux, 2011) y muchas veces acompañaron políticas públicas que consolidaron tales miradas (Leyton, Huertas, 2012; Durán, 2014). Dentro de este marco, el deporte y la actividad física adquieren gran relevancia en tanto fueron ejes de políticas estatales de corte eugénico en las primeras décadas del siglo XX. En torno a esto último, existió un complejo entrelazamiento entre medicina, educación, nacionalismo, género y actividad física que buscó fortalecer el cuerpo social nacional a través de, entre otras cosas, la expansión de la educación física.

En efecto, según Manuel Durán (2014), "los agentes médicos se abocaron a establecer las escuelas como único espacio legítimo de formación física y moral. Para ello, desde la década de 1870, médicos como Adolfo Murillo propusieron planes de educación física". Estos primeros impulsos a la educación física tendrán un carácter marcadamente militarista, muy influenciado por la escuela germana (Serrano, Ponce de León, Rengifo, 2013). Ahora bien, las visiones militaristas de la educación física de Murillo y J.J Aguirre van en franca retirada a finales del siglo XIX, siendo reemplazadas por visiones de corte higienista y eugénico (Martínez, 2012), donde la gimnasia sueca - y en particular la figura de P.H. Ling ${ }^{1}$ - cobra vital importancia a partir de la argumentación científica que sustenta las rutinas y sentido de los ejercicios que la componen. En específico, el debate entre Joaquín Cabezas y Francisco Jenschke, en el Segundo Congreso Nacional Pedagógico de 1902, será decidor para que esta modificación comience a aplicarse en las instituciones educativas (Serrano, Ponce de León, Rengifo, 2013).

Con respecto a la lógica higienista y eugénica implicada en la escuela sueca, Felipe Martínez (2015a) afirma que:

Basados en teorías provenientes de la higiene social, el darwinismo, la eugenesia o en los principios de anatomía, la fisiología y la mecánica, los especialistas médicos fueron receptivos en acoger a la ejercitación como un importante medio de salud. Si en un principio sus efectos fueron pensados bajo prescripciones terapéuticas, acabarían transformándose en una 'novedosa y saludable' rutina higiénica, siendo un agente de cambio para hombres y mujeres que deseaban transformar sus hábitos y vigorizar sus cuerpos. 
Sumado a lo anterior, Durán (2014) también enfatiza en la relevancia de la educación física, especialmente infantil, para alcanzar el canon de la "verdadera belleza, que no era otra que la obtenida naturalmente por quien supiera cultivar el ejercicio físico". En ese sentido, el imaginario sobre la Grecia antigua, especialmente su estatuaria, son algunos de los modelos para encarnar esta dimensión estético corporal (Martínez, 1999; Chávez, 2009), cuestión bastante explícita en la fuente que aquí presentamos.

En buena medida, estos ideales de belleza se presentan como antípodas de las consecuencias corporales de vicios sociales como el sedentarismo, el alcoholismo o la drogadicción, todos los cuales buscaban ser combatidos, entre otras formas, a través de la educación (Martínez, 2015a; Elsey, 2011; Durán, 2014; Yañez, 2016) y de organizaciones higiénicas de la sociedad civil como La Liga Chilena de Higiene Social (LCHS), o la Asociación Nacional de Educación (ANE) (Subercaseaux, 2011) que fueron los primeros que proclaman el higienismo como clave para la "lucha por la existencia" (Martínez, 2015a).

Como una suerte de síntesis entre ambas posiciones se encuentra la creación del Instituto de Educación Física y Manual (IEF), en 1906 (Muñoz, 2001), institución que representa la llegada de este proyecto corporal-normativo a la alta política pública, y que será capitaneada por Joaquín Cabezas, adalid de la gimnasia sueca y participante en otras instituciones similares. Esta institución tendrá como principal objetivo la formación de profesores de dicha asignatura, aunque ésta incluía tanto las ciencias del movimiento físico como también actividades manuales y oficios (Serrano, Ponce de León, Rengifo, 2013), condición que continuó hasta 1918, cuando llega a la Universidad de Chile y se profesionaliza a partir de las mismas prerrogativas que el Instituto Pedagógico, perdiendo las últimas palabras de su nombre.

Como bien señala Martínez (2015a), el gobierno de Ibañez significa un cambio profundo en las concepciones de la educación física. Las nuevas leyes tienen como premisa que "la educación física es una atención preferente del Estado y deben recibirla todos los habitantes de la república" (Muñoz, 2001).

De este modo, los objetivos que Ibáñez tenía en su programa deportivo eran dos: "promover la incorporación de la cultura física en los hábitos de los chilenos e impulsar la construcción de más lugares para la práctica deportiva" (Millán, 19 mayo 2017). En ese sentido, y como lo señala Rodrigo Millán, el afán por construir equipamiento e infraestructura deportiva será una misión importante de este periodo (1927-1931), y tales obras constituyeron "piezas importantes del proceso de modernización urbana y de la vida cotidiana de quienes utilizaban aquellos espacios (Millán, 19 mayo 2017). Sumado a esto, se genera una constelación de nuevas organizaciones como el Ministerio de Higiene, se alargan las carreras de profesor de educación física a cuatro años, sumando en sus mallas curriculares cursos de periodismo deportivo y de deportes específico como tenis, volleybol, fútbol, boxeo, lucha, entre otros (Martínez, 2015a). Además, se crea el Departamento de Educación Física (DEF), que sirvió como organismo que fiscalizaba y hacía inspecciones higiénicas en colegios y recintos deportivos (Martínez, 2015a). Sin embargo, en muchos casos esta búsqueda queda solo en deseos o intenciones.

En cualquier caso, si bien esta búsqueda comienza a darse fuertemente en el gobierno de Ibáñez del Campo, especialmente inspirado en la política de construcción de parques y plazas uruguayas (Millán, 19 mayo 2017) - cuyo valor y necesidad para la educación física 
es parte de las discusiones del Primer Congreso Nacional de Educación Física (Arellano, 1942) -, es en las administraciones posteriores que se construirán algunas de edificaciones más significativas como el Estadio Nacional en 1938.

En efecto, durante el primer gobierno del Frente Popular (1938-1942) se dará una política de promoción al patriotismo y defensa de la raza que buscará mejorar las condiciones innatas de los chilenos bajo una lógica de control social y racismo nacionalista (Cárcamo, 2015), que tendrá como punto culminante la creación de la institución Defensa de la raza y aprovechamiento de las horas libres, sindicado como uno de los inicios de la política deportiva del Estado de Chile (Muñoz, 2001), que buscaba promover la cultura deportiva y la actividad física dentro de la población adulta y obrera, especialmente.

En todo caso, esta institución generó una importante polémica con los profesores de educación física que consideraban que el énfasis debía estar puesto en la juventud (Bisquertt, 1942-1943), así como también, que Defensa de la raza... se inmiscuía indebidamente en labores propias de los profesores (Pacull, 1942). En ese sentido, el magisterio nacional del ramo ponía énfasis más bien en la necesidad de contar con una ley de educación física que "propenda al control y divulgación de la cultura física", cuyo proyecto fue elaborado por Joaquín Cabezas y Luis Bisquertt, entre otros, en 1938 (Pacull, 1942; Bisquertt, 1942-1943). Otra de las críticas más interesantes dice relación con el poner la cultura física por sobre el mejoramiento de las condiciones materiales de la población, sin las cuales sería imposible lograr la "alegría de vivir", propósito declarado de Defensa de la raza... (Pacull, 1942).

En términos de infraestructura, el Estadio Nacional es fundamental para el fortalecimiento de la raza según Joaquín Orellana, su administrador en 1942. Afirmaba que la salud es "base granítica del progreso de la humanidad", y que en su defensa los "medios físicos que fortalecen el cuerpo" son muy importantes, debido a lo cual el Estadio Nacional tiene que jugar un papel central. Sin embargo, el Estadio Nacional también fue eje de polémicas con los profesores de educación física que, a través del Boletín de Educación Física, fundado por Miguel Maraboli en 1933 (Valenzuela, 1940), realizaban una "campaña sostenida con insistencia, casi con majadería" (Díaz, 1940) con el objeto de lograr que el Estadio se convierta en el nuevo local del Instituto de Educación Física, pues éste se encuentra en un edificio que "no posee terrenos deportivos ni canchas de ninguna especie. Apenas dispone de un solo gimnasio y de una vieja piscina en mal estado" (Bisquertt, 1942). Es más, para Bisquertt, que era un firme defensor de la educación física social, ${ }^{2}$ el Estadio debió ser la cúspide de una nación "que ha establecido la educación física primaria, secundaria, universitaria y popular" (Bisquertt, 1942) y no el punto de partida para la "vasta obra de la educación física de la juventud, progresiva y completa" (Bisquertt, 1942-1943).

Esta noción de educación física social, trabajada por Bisquertt, incluso como una forma de avanzar hacia la paz en el contexto de la Segunda Guerra Mundial (Bisquertt, 1942-1943), comenzó a chocar con concepciones más profesionalizantes y vinculadas al espectáculo que quitaban cabida a las lógicas más eugénicas (Ostic, 1978) o amateur, cosa que en el caso del fútbol ha sido analizado por Jorge Iturriaga (2008), y en la actualidad está siendo investigado por Álex Ovalle en relación con la profesionalización del boxeo. De este modo, en el periodo que reseñamos parece existir una búsqueda por construir una relación orgánica entre el cultivo del cuerpo y la búsqueda por el fortalecimiento nacional, con el objetivo 
de poner el interés de Chile por sobre determinados grupos humanos o clases sociales. $\mathrm{O}$ si somos más punzantes, de hacer pasar el interés particular por el interés general.

El fortalecimiento nacional no fue probativo de la gimnasia, sino que los deportes más populares también estuvieron al servicio de ello. La investigación de Alex Ovalle y Daniel Briones (2013) da cuenta cómo la revista Zig-Zag desde 1905 a 1912 promueve un componente de nacionalismo que permite entender al deporte como un dispositivo de unificación de la nación por sobre las perspectivas clasistas (Ovalle, Briones, 2013). Esta búsqueda por erosionar los lazos de clase en desmedro de los de nación está acompañada por "una función pedagógica moral, que acondicionaría a los sujetos a seguir instrucciones, en pos de la transformación del trabajador y del educando en ciudadanos capaces de discernir las necesidades nacionales" (Ovalle, Briones, 2013, p.54).

Este tipo de intentos por perfeccionar la obediencia obrera a través del deporte la podemos ver también en iniciativas del paternalismo industrial. Un caso de ello es la promoción de la educación física entre los mineros de Lota con el objetivo de generar "obreros sanos, físicamente aptos para resistir el duro trabajo de las minas, y por consecuencia, un capital hombre más valioso que el actual" (Rosa Reed, 1942), temática investigada actualmente por Oscar Peñafiel (2016) en el caso de la minería de Lota.

Las anteriores son algunas de las múltiples búsquedas por subordinar los intereses o expectativas obreras o populares a los intereses empresariales o estatales, cuestión que será resistida y criticada por instancias como el Congreso de Cultura Obrera (COC), realizado en 1937 y resaltado por Juan Carlos Yáñez (2016). En ese encuentro se establece la división de ocho horas de trabajo, ocho de descanso y ocho de recreación.

Allí es posible ver como los trabajadores fueron capaces de generar sus propias instancias de diálogo y discusión respecto a qué hacer con sus horas libres y, en especial, en lo que respecta a la actividad física. En efecto, este congreso apuntaba al fomento de la culturización obrera y, especialmente, a "la necesidad de orientar la obra cultural obrera chilena difundiendo la instrucción a base de la utilización de las horas libres de los trabajadores y fomentando el arte nacional en sus distintas manifestaciones" (Yañez, 2016).

En esta propuesta hay un interés por aumentar la capacidad intelectual de los obreros, pero además mejorar las condiciones físicas de los sectores populares. Por ende, aunque no hay un discurso explícito de "mejoramiento de la raza" sí hay una ligazón práctica con los objetivos que tiene el Frente Popular. No es de extrañar entonces que organismos estatales trabajen en conjunto con estas propuestas del COC.

\section{Luis Bisquertt y su lugar en el debate sobre la actividad física y la eugenesia}

Luis Bisquertt Susarte (1895-1970) estudió en Rengo y luego en el Internado Nacional Barros Arana, se tituló de médico y profesor de educación física en la Universidad de Chile en 1926 y fue cara visible de la tendencia eugénica en la educación física desde los años 1920. Tuvo un importante rol como columnista en la masiva revista de deportes Los Sports (Martínez, 2015a, 2015b), plataforma que sin duda lo llevó a ser visibilizado como un experto que velaba por la masificación del conocimiento sobre actividad física, incluso en los medios más populares, por fuera de lo académico (Martínez, 2015a). 
Así, mientras Joaquín Cabezas vive sus últimos años como actor central del campo de la educación física eugénica e higiénica, Bisquertt aparece con una versión fresca que continúa y profundiza su perspectiva cuyo referente sigue siendo P.H. Ling (Bisquertt, 1951). Entonces, no es de extrañar que hacia 1943 Bisquertt ya fuese director del Instituto de Educación física, posición que mantendrá hasta su retiro de la Universidad de Chile en Santiago, en 1966 (Salas, 1980), cuando se ubicó como director de la Escuela de Educación Física en la Universidad del Norte hasta su muerte en 1970.

$\mathrm{Su}$ importancia fue tal que se crearon numerosos premios en Brasil y Chile en su nombre, siendo puesto a nivel de Enrique Romero Blest o Beleván García en Latinoamérica (Lara, 2008). En 1978, Zvonimir Ostic publica en libro homenaje donde resalta las cualidades de Bisquertt, conectando su amor a la Grecia antigua y a la educación física con un humanismo totalizante, y resaltando el afán eugénico y embellecedor de la raza chilena.

La frescura de los argumentos de Bisquertt radica tanto en los objetos de investigación que tiene como en los modelos ejemplares que aplica para sus estudios. Señala Martínez que tanto la fatiga como el sedentarismo son parte relevante del corpus de Bisquertt, las cuales ya había estudiado en Europa, basándose en los estudios del italiano Angelo Mosso y del francés Phillippe Tissié (Martinez, 2015b), y que el chileno vinculaba a la degeneración de la raza que debía ser revertida a través del deporte. Así, su situación contemporánea es juzgada por su contraste con la belleza griega, ${ }^{3}$ propiciada especialmente por una política deportiva social y general que favorecía cuerpos modelados y reflejados en su estatuaria (Bisquertt, 1936-1937).

En específico, el texto acá presentado, "Aspectos de la educación física", fue publicado por la Revista de Educación, del Ministerio de Educación Pública, chileno en octubre de 1930, donde podemos ver encarnadas y prefiguradas varias de las posiciones que tomó Bisquertt frente a las discusiones que hemos venido desarrollando, especialmente vinculadas a una concepción eugénica de la educación física que, si bien se pone en explicito contraste con la comprensión guerrera de la misma - que llegará a su cenit algunos años más tarde en la Alemania Nazi (Chapoutot, 2013; Roche, 2013) -, también da cuenta de un punto de partida común: el canon clásico como modelo de cuerpo ideal (Echeverría, 2007).

En efecto, aunque este texto es previo a la misión llevada a cabo por Bisquertt en Europa (financiada por la Universidad de Chile) para analizar sus sistemas de educación física, "Aspectos de la educación física" prefigura los juicios que el chileno emitirá con respecto a la política de educación física nacional socialista: por ser fundamental en la formación escolar, así como por su carácter social y obligatorio, ésta debía ser emulada por todas las naciones civilizadas, aunque el objetivo belicoso y racista que persigue sea condenado (Bisquertt, 1937). Cabe señalar que, en el ámbito gimnástico, el modelo espartano en particular (Roche, 2013), pero el canon clásico, en general (Chapoutot, 2013), jugaron un rol importante en el imaginario nacional socialista, cuestión que Bisquertt replica afirmando que en la Alemania Nazi "una Grecia espartana que renace, amplificada, intensificada, agigantada" (Bisquertt, 1937).

En esa línea, dentro del texto de Bisquertt - y en buena parte de su producción escritural, así como en otros textos de la época - es posible encontrar una concepción ideal del cuerpo y la belleza modelada por las estatuas griegas, en una operación que se remonta a las Reflexiones sobre la imitación de las obras griegas en la pintura y la escultura, de Johann 
Joaquim Winckelmann (Mas, 2007), donde se comienza a asentar una concepción de lo griego que fue fundamental en las representaciones de lo clásico que jugarán un rol en las múltiples formas de legitimación y construcción de hegemonía en torno a ideas racistas (Bernal, 1991) y colonialistas (Goff, 2005).

Hacemos referencia a Winckelmann porque, según Salvador Mas, una de las bases del pensamiento winckelmanianno sería la contradictoria necesidad de recuperar aquello que se ha perdido para siempre, y que se evidencia paradigmáticamente en las estatuas griegas: lo sublime, es decir, la armónica unicidad de la naturaleza y el hombre, que contiene la multiplicidad de manifestaciones de la belleza.

Esto último es central para nosotros por dos razones. Primero, porque Bisquertt busca resolver dicha contradicción a partir del rol de la educación física como eje de la búsqueda por la belleza plástica, ejemplificada también por los cuerpos helénicos, pero cuyo sentido se encuentra totalmente imbricado a la salud y la normalidad. En efecto, ante el diagnostico de una "modernidad adiposa", Bisquertt (1930) afirma la necesidad de promover la educación física eugénica y científica que nos permita retomar la senda de los pure-sang humanos.

En segundo lugar, nos encontramos con la relevancia que se le asigna al arte en esta búsqueda. En efecto, dentro de "Aspectos de la educación física" se argumenta que la desviación del canon artístico, de uno efectivamente bello y normal (clásico) a uno degenerado (moderno), estaría dada por la naturaleza mimética del arte para con la sociedad en que este se desarrolla. En ese sentido, lo anterior sería consecuencia de la deformación de los cuerpos modernos y contemporáneos, condición apologizada por Bisquertt y que busca resolverse a partir de la educación física. Otro aspecto significativo de la relevancia del arte dentro del ámbito de esta disciplina dice relación con su afán de totalidad (Pinilla, 1937), búsqueda que incluso llega a afirmar que solo la educación física científica posibilita "la unidad de la acción educativa en conexión con la totalidad del hombre y la totalidad de la vida" (Romero, 1944). Es decir, el hiato entre lo ideal y lo real podría cerrarse a partir de la acción de la educación física. Y en esa línea, el logro de la belleza plástica sería un síntoma de tal reunión y condición necesaria para el mejoramiento racial de la nación. Ahora bien, esto no puede realizarse sin el apoyo del Estado y de la cuantificación de la educación física para su "mejoramiento biológico" (Bisquertt, 1946).

En torno a esto último, y especialmente en vínculo con lo paradigmático que resultaba la belleza clásica como signo de civilización en el contexto decimonónico latinoamericano - mirada que comenzará a ser relativizada durante el siglo XX mediante, por ejemplo, la igualación del mundo indígena precolombino al helénico (Mistral, 1978; Prudencio, 1990) -, es interesante pensar las perspectivas de Bisquertt como una suerte de búsqueda por sintetizar el humanismo civilizatorio con el nacionalismo más organicista.

En este sentido, entendemos que las cuestiones puestas en juego por el texto que reproducimos a continuación implican un aporte para la comprensión de la historia de la salud y la ciencia en América Latina, así como enriquecen el conocimiento de las políticas eugénicas, especialmente en el contexto chileno de la primera mitad del siglo XX, aunque pueden encontrarse también replicadas en otros países del continente (Chavez, 2009; Martínez, 1999). 


\section{NOTAS}

${ }^{1}$ La relevancia de Ling en Chile puede consignarse en varios informes sobre las Lingeadas suecas - versión local de Juegos Olímpicos -, así como en una calle que lleva su nombre, ubicada muy cerca del ex Instituto Pedagógico, en la santiaguina comuna de Ñuñoa.

${ }^{2}$ Definida por Zvonimir Ostic (1978), en un homenaje a Bisquertt como: doctrina social que se compromete con fundamentales objetivos de formación y desarrollo; de recreación y superación humana; de protección sanitaria y elevación de la calidad biológica; de rendimiento productivo y unidad nacional; de elevación espiritual y equilibrio social; de expresión de talentos y manifestación vernácula; de compensación sicofísica y espiritual; en fin, esta doctrina aspira a la preservación y evolución del género humano, salvándolo a la vez de los deterioros que podrían ocasionarle los efectos de nuestra civilización tecnológica, a través de una acción "rehumanizadora", se transformó en el fuego en que ardió su pasión humanista y en el que se consumió, aparentemente de manera inútil, mucha de su labor infatigable.

${ }^{3}$ Cabe destacar que no solo los cuerpos griegos son recuperados con el afán de contraponerse a esta realidad, sino que también los de los "primitivos de vida libre en la naturaleza". Si bien no lo evidencia en el escrito que se presenta a continuación, podemos pensar que dicha frase se vincularía al pueblo mapuche precolombino y de inicios de la conquista, especialmente porque algunos años antes (Bisquertt, 1926) Bisquertt tomaba pasajes de La Araucana para demostrar la belleza plástica del pueblo mapuche, lograda a partir de, entre otras cosas, la educación física. En un registro similar, es posible encontrar proyecciones de las características araucanas antiguas hacia la nación chilena moderna, entre las que se encuentran especialmente el vigor, la fuerza o el coraje, las que se derivan también de la actividad física de los indígenas, siempre usando La Araucana como referente central (Galdames, 1933; Plath, 1945; Chihuailaf Nahuelpan, 2010; Bisquertt, 1930).

\section{REFERENCIAS}

ARELLANO, Ema.

Plazas de juegos. In: Ministerio de Educación Pública, Primer Congreso de Educación Física. Santiago de Chile: Imprenta Universitaria, p.303-321. 1942.

BERNAL, Martin. Atenea Negra. Barcelona: Crítica. 1991.

BISQUERTT, Luis.

II Lingiada: Charlas sobre la segunda de las reuniones internacionales de gimnasia realizadas en Estocolmo en homenaje a la memoria de Per Henrik Ling, en julio de 1949 con el nombre de Lingiadas. Santiago: Universidad de Chile. 1951.

BISQUERTT, Luis.

Discurso del director del instituto Dr. Luis Bisquertt. Boletín de Educación Física, n.45, 46-47, p.93. 1946.

BISQUERTT, Luis.

Local para el Instituto de Educación Física. Boletín de Educación Física, n.25, p.1-2. 19421943.

BISQUERTT, Luis.

Sobre la educación física de ahora. Santiago de Chile: Imprenta Universitaria. 1937.

BISQUERTT, Luis.

La educación física en Europa. Boletín de Educación Física, n.10-11, p.437-447. 1936-1937.
BISQUERTT, Luis.

Aspectos de la educación física. Revista de Educación, n.22, p.664-675. 1930.

BISQUERTT, Luis

Educación física y belleza plástica. Revista Médica de Chile, p.26-29. 1926

CÁRCAMO, Nicolás

Enfermo, quiltro y chileno. Eugenesia y degeneración de la raza en Chile. 1937-1941.

In: Leyton, César; Palacios, Christián; Sanchéz, Marcelo (Ed.). Bulevar de los pobres: racismo científico, higiene y eugenesia en Chile e Iberoamérica siglos XIX y XX. Santiago: Ocho Libros. 2015.

CHAPOUTOT, Johann.

El nacionalismo y la antigüedad. Madrid: Abada. 2013.

CHÁVEZ, Mónica.

Construcción de la nación y el género desde el cuerpo. La educación física en el México posrevolucionario. Desacatos, n.30, p.43-58. 2009.

CHIHUAILAF NAHUELPAN, Elicura

Los escritos de Manquilef González. Anales

de la Universidad de Chile. Edición especial

Bicentenario de Chile, p.65-85. 2010.

CORREA, Sofía et al.

Historia del siglo XX chileno: balance paradojal. Santiago: Editorial Sudamericana. 2008. 
DÍAZ, Humberto.

Nuevo local para el Instituto de Educación Física. Boletín de Educación Física, n.25, p.2-3. 1940.

\section{DURÁN, Manuel.}

Género, cuerpo, gimnasia y sexualidad en los manuales educacionales higienistas y eugenésicos en Chile, 1870 -1938. Revista de Historia Social y de las Mentalidades, v.18, n.1, p.35-58. 2014

ECHEVERRÍA, Bolívar.

Imágenes de la blanquitud. In: Lizarazu, Diego. Sociedades icónicas: historia, ideología y cultura en la imagen. Ciudad de México: Siglo Veintiuno. Disponible en:<http://www.bolivare. unam.mx/ensayos/blanquitud.html>. Acceso en: 27 jan. 2019. 2007.

\section{ELSEY, Brenda.}

Citizens and sportsmen: futbol and politics in twentieth-century Chile. Austin: University of Texas Press. 2011.

\section{GALDAMES, Luis.}

El carácter araucano en el Poema de Ercilla. Anales de la Universidad de Chile, n.11, p.40-53. 1933.

GOFF, Barbara.

Classics and colonialism. London: Duckworth. 2005.

\section{ITURRIAGA, Jorge.}

"Aunque ganes o pierdas" el fútbol profesional en Chile, una perspectiva histórica. In: Herrera, Rodrigo; Varas, José. Fútbol, cultura y sociedad. Santiago: Universidad Academia de Humanismo Cristiano. p.23-43. 2008.

LARA, Horacio.

Doctor Luis Bisquertt Susarte (Homenaje en el Acto del Centro de Egresados realizado el 18 de noviembre de 2008 en el auditorio "Dr. Luis Bisquertt Susarte" del campus "Joaquín Cabezas García".) Disponible en: < https://www.ceyaf. com/visionarios-2/>. Acceso en: 27 jan. 2019. 2008.

LEYTON, Cesar; HUERTAS, Rafael.

Reforma urbana e higiene social en Chile. La tecno-utopía liberal de Benjamín Vicuña Mackenna (1872-1875). Dynamis, n.32, v.1, p.2144. 2012.

\section{LEYTON, Cesar; PALACIOS, Cristián; SÁNCHEZ,} Marcelo.

Bulevar de los pobres: racismo científico, higiene y eugenesia en Chile e Iberoamérica siglos XIX y XX. Santiago: Ocho Libros. 2015.

MARIÁTEGUI, José Carlos.

La unidad de la América indo-española. Disponible en: <https://www.marxists.org/ espanol/mariateg/1924/jul/06.htm>. Acceso en: 15 mar. 2018. 1924.

MARTÍNEZ, Felipe.

Cuerpos en movimiento: circulación y generación de conocimientos en torno a la ejercitación de los cuerpos. Santiago de Chile. 1880-1931. Tesis (Maestría) - Departamento de Ciencias Históricas, Universidad de Chile, Santiago. 2015a.

MARTÍNEZ, Felipe.

Del recargo intelectual al desequilibrio nervioso-muscular: la ejercitación del cuerpo como terapéutica en el Chile urbano de principios de siglo XX. Nuevo Mundo Mundos Nuevos. Disponible en: <http://nuevomundo. revues.org/68312>. Acceso en: 27 jan. 2019. 2015 b.

MARTÍNEZ, Felipe.

Hacia una pedagogía del cuerpo. La educación física en Chile: 1889-1920. Ágora para la EF y el Deporte, n.14, v.3, p.320-331. 2012.

MARTINEZ, Francoise.

¡Que nuestros indios se conviertan en pequeños suecos! la introducción de la gimnasia en las escuelas bolivianas. Bulletin de l'Institut Français d'Etudes Andines, Institut Français d'Etudes Andines (IFEA), v.28, n.3, p.361-386. 1999.

MAS, Salvador

La Grecia de Winckelmann. In: Winckelman, Johann. Reflexiones sobre la imitación de las obras griegas en la pintura y escultura. Ciudad de México: Fondo de Cultura Económica. 2007.

MILLÁN, Rodrigo.

Cultura física, higiene y arquitecturas deportivas en el régimen de Carlos Ibáñez del Campo (1927-1931). Documento presentado en el II Taller de Historia, Universidad Católica de Chile. 19 mayo 2017.

MISTRAL, Gabriela.

El tipo del indio americano. In: Céspedes, Mario (Comp.). Recados para América: textos de Gabriela Mistral. Santiago de Chile: Revista Pluma y Pincel/Instituto de Ciencias Alejandro Lipschutz. Disponible en: <http://www. gabrielamistral.uchile.cl/prosa/indio.html>. Acceso en: 27 jan. 2019. 1978.

MUÑOZ, Cristián.

Historia de la Dirección General de Deportes y Recreación: las políticas estatales de fomento al deporte. DIGEDER 1948-2001. Santiago: Departamento de Comunicación Social, IND. 2001.

ORELLANA, Joaquín.

Rol del estadio en el fortalecimiento de la raza. In: Ministerio de Educación Pública. Primer 
Congreso de Educación Física. Santiago de Chile: Imprenta Universitaria. p.295-301. 1942.

OSTIC, Zvonimir.

Dr. Luis Bisquertt "humanista de América" y precursor de la educación física social de Chile. Santiago: Camilo Henríquez Ltda. 1978.

OVALLE, Alex; BRIONES, Daniel. "Producir hombres de cuerpo y carácter": el fútbol a través de la revista Zig-Zag, Santiago y Valparaíso (1905-1912). Revista de Ciencias Sociales, n.31, p.39-60. 2013.

PACULL, Juan Emilio.

Defensa de la raza y ocupación de las horas libres. In: Ministerio de Educación Pública. Primer Congreso de Educación Física. Santiago de Chile: Imprenta Universitaria. p.167-173. 1942.

PEÑAFIEL, Oscar.

Cuerpos fuertes, conciencias dóciles. La construcción del obrero soñado a través del deporte en la cuenca carbonífera. 1920-1950. In: Videla, Enzo et al. El orden fabril: paternalismo industrial en la minería chilena. 1900-1950. Valparaíso: Editorial América en Movimiento. p.167-189. 2016.

PINILLA, Norberto.

La filosofía del arte por Norberto Pinilla: profesor de introducción a la estética en el Instituto. Boletín de Educación Física, n.14, p.627628. 1937.

PLATH, Oreste.

Juegos, ejercicios y armas araucanos. Boletín de Educación Física, año 11, n.43-44, p.294-302. 1945.

PRUDENCIO, Roberto.

Sentido y proyección del Kollasuyo. In: Prudencio, Roberto. Ensayos históricos. La Paz: Editorial Juventud. 1990.
ROCHE, Helen.

Sparta's German children: the ideal of ancient Sparta in the Royal Prussian Cader-Corps, 18181920, and in national-socialist elite schools (The Napolas), 1933-1944. Swansea: The Classical Press of Wales. 2013.

ROSA REED, Hugo.

La educación física en Lota (Resumen). In: Ministerio de Educación Pública. Primer Congreso de Educación Física. Santiago de Chile: Imprenta Universitaria. p.323-328. 1942.

ROMERO, Enrique.

Ensayo de un planteo total del problema de la educación física. Boletín de Educación Física, n.4142, p.394-400. 1944.

SALAS, Rosauro.

Rasgos de un humanista: el Dr. Luis

Bisquertt Susarte. Enfoques educacionales, n.6, p.95. Disponible en: <http://www. bibliotecanacionaldigital.cl/bnd/628/w3article-216863.html>. Acceso en: 27 jan. 2019. 1980.

SERRANO, Sol; PONCE DE LEÓN, Macarena; RENGIFO, Francisca.

Historia de la educación en Chile. t.2: la educación nacional (1880-1930). Santiago: Taurus. 2013.

SUBERCASEAUX, Bernardo.

Historia de las ideas y de la cultura en Chile: desde la independencia hasta el bicentenario. v.2. Santiago de Chile: Imprenta Universitaria. 2011.

VALENZUELA, Manuel.

Un nuevo año de vida. Boletín de Educación Física, n.25, p.1. 1940.

YAÑEZ, Juan Carlos.

Trabajo y políticas culturales sobre el tiempo libre: Santiago de Chile, década de 1930. Historia, v.2, n.49, p.595-629. 2016. 


\section{Luis Bisquertt Susarte. Aspectos de la Educación Física. In: Revista de Educación, año 2, n.22, p.664-675. Oct. 1930.}

El fin de la Educación, dice Guyau, es desarrollar todas las posibilidades de un ser. Una de tales posibilidades es la adquisición de la belleza plástica, asunto que, lejos de tener un interés exclusivamente estético, también la tiene - y muy grande - desde el punto de vista Biológico.

Es que el concepto de belleza plástica está ligado íntimamente al de salud, al de valor funcional orgánico. La perfección de la forma anatómica, interna o externa, macroscópica o microscópica, corresponde, en cada ser, a la perfección y normalidad de la función fisiológica. Y la forma anatómica correcta o normal, siempre ha sido considerada como bella, en el sentido de provocar emoción estética, en el sentido de atraer, de agradar interiormente. Las obras cumbres de la estatuaria griega ¿Qué son, sino formas anatómicas perfectas?

Existe, como digo, una relación directa entre forma y función. Los trastornos de esta, a la larga, repercuten sobre ella y la desvían. Si consideramos una enfermedad cualquiera, aguda o crónica, infecciosa o no, encontraremos siempre, al lado del trastorno funcional, la alteración de la forma, ya evidente a la simple vista en el aspecto externo, ya oculta y microscópica en la intimidad de los tejidos. Ya, desde luego, el estado permanente de salud se transparenta en la amplitud del tórax, la belleza y tonicidad de los modelados musculares, la expresión alegre o tranquila del semblante, el brillo del cabello, la viveza del gesto, la soltura y la elasticidad en el andar, la tendencia a la actitud erguida, de extensión. En el estado de enfermedad, en cambio, la gracia de la forma termina por decaer con la alteración del modelado muscular; se pierde la viveza y la soltura; el rostro refleja malestar interno y la actitud de flexión de las pasiones tristes, del dolor, domina.

Cada especie, cada raza, dentro de la variabilidad de sus propios individuos, presenta un tipo central, en el cual las características del grupo se manifiestan con mayor constancia. Esta especie de término medio constituye, podemos decir, un tipo etalón, lo más hermoso dentro de la especie: es el "pure-sang". Ahora bien, este tipo junto con ser el más hermoso, es también el de mayor salud y fortaleza y, por consiguiente, de mayores aptitudes en la lucha por la vida. La naturaleza nos muestra esto dondequiera que miremos. ¿No es más bello, no es más apto en su áspera lucha por la vida el guanaco esbelto, vagando en la desierta cordillera, que el vacuno de raza, engrasado en cómodos establos o en bien cuidados potreros? Aquel, perpetuamente fugitivo del hombre, es su enemigo aleve, relegado por él en las cumbres desoladas, conserva, gracias a la tenaz batalla con el medio, sus mejores aptitudes físicas, aptitudes que se revelan en la gracia de su forma. Al menos atisbo de un peligro, que reconoce a enormes distancias, corre, como si le pusieran alas en el lomo, por el borde mismo de los precipicios. Musculoso y ágil, atraviesa con gran tino los rodados, y trepa seguro en prodigios de equilibrio, por las peñas puntiagudas y empinadas. Este en cambio, sin necesidad de actuar, rodeado de atenciones, seleccionado y cebado con esmero para obtener un tipo especial de carnadura, ha perdido, en realidad, las aptitudes requeridas para la supervivencia del más apto en el seno de la naturaleza. Y su forma va desviándose hacia el tipo buscado por el hombre en su propia conveniencia. 
Es un hecho que los individuos que más se alejan del tipo fundamental de su especie, son los que menos resisten y más fácilmente perecen cuando las condiciones del medio ambiente les son adversas. Así se ha comprobado en las aves marinas arrastradas por los vientos durante las grandes tempestades $\mathrm{u}$ obligadas accidentalmente a efectuar largas inmigraciones.

Ahora bien, el animal hombre, como los otros seres, es también tanto más bello y más fuerte mientras más se acerca al canon de su raza. Y de esto se deduce la necesidad de precisar ese etalón humano que habría que ser tomado como modelo y punto de comparación. Sin embargo, muy difícil resulta conseguirlo, por cuanto los pueblos que habitan la tierra difieren bastante unos de otros, y aún pueden encontrarse en vías de variación. El sajón, el bochismano, el esquimal, el francés, el chino, el aimara, todos, presentan características morfológicas propias. Solo en la talla ya hay grandes diferencias. Así, el holandés tiene por término medio, $1,78 \mathrm{~m}$ de altura. El aimara 1,57, el chino 1,63, el bochismano 1,35 solamente. Las razas andadoras del desierto, las razas montañesas, las que pueblan las selvas tropicales o las comarcas heladas de Groenlandia y Alaska son, naturalmente, distintas pues, el hombre, como los demás seres, es, en cierto modo, hechura del ambiente en que vive y en él también, a través del tiempo, se hace sentir lentamente la influencia diversificadora de la adaptación.

Muy conocidas por la observación y el experimento, las variaciones que el medioambiente provoca en animales y plantas, no han podido comprobarse en el hombre en forma tan exacta y evidente. Sin embargo, la ley de Quetelet ${ }^{1}$ y los polígonos de frecuencia aplicados al hombre, demuestran que éste se encuentra también dentro de las reglas de las variaciones de las especies. Y la gran guerra y el período de la post-guerra han demostrado tristemente, no sólo efectos de la selección negativa efectuada por la hecatombe, sino también fatales desviaciones de las curvas de variación de la generación hipoalimentada y golpeada por la catástrofe. Es tal vez la primera vez que el médico, con fichas biométricas y estadísticas en mano puede enrostrar al preparador de futuras guerras, el odio atentado hacia la especie.

Por otra parte, las variaciones del tipo humano son mucho más numerosas que los que a primera vista pudiéramos creer. Sabemos que en millones de hombres no hay dos iguales, y si eso solo en el rostro lo apreciamos, es porque estamos habituados a mirar en él; pero el resto del cuerpo y los órganos internos presentan millares y millares de diferenciaciones, a pesar de sus analogías. Citemos solo la diversidad de longitud y posición del intestino, la pasmosa variedad de las circunvoluciones del encéfalo, las arborizaciones arteriales, los pliegues y surcos de las manos etc. etc., aparte de las infinitas diferencias en la estructura de los tejidos.

\footnotetext{
${ }^{1}$ La que se refiere a la distribución de los caracteres individuales dentro de la especie, distribución que se relaciona con el desarrollo del binomio de Newton $(\mathrm{a}+\mathrm{b})$. Si se examina un gran número de individuos, 1.000 por ej.: bajo el punto de vista de un carácter expresable en cifras, como la talla, y se colocan en líneas las cifras obtenidas, desde la más baja a la más alta, veremos que el mayor número de individuos examinados presentarán una talla que corresponde a la parte media de la línea, decreciendo el porcentaje hacia los extremos, exactamente como en el desarrollo del binomio de Newton (consúltese al respecto cualquier texto de biología que estudie las leyes de la herencia).
} 
De modo entonces, que fijar un canon humano perfecto, absoluto y definitivo, no parece posible, ni aún para determinadas razas, sub-razas o pueblos. No obstante, se ha querido restablecer basándose en el gran número de mediciones hechas en europeos (Dr. Topinard). Pero aquí chocamos frente a otra gran dificultad. Y es que no podemos considerar normal al tipo término medio que esas mediciones pongan de manifiesto por numerosísimas que ellas sean. Se refieren a una muchedumbre sedentaria en su inmensa mayoría, que desde antiguo y por muchas generaciones vive alejada de las leyes naturales. Las alteraciones funcionales así provocadas han debido repercutir necesariamente la forma externa, apartándola, paulatinamente, de la morfología normal. Efectivamente, si comparamos dos tipos opuestos: un atleta de musculatura y esqueleto bien desarrollados y mantenidos por la práctica del ejercicio y de la higiene, y, por otro lado, un oficinista o profesional de familia sedentaria inmovilizado desde niño por el carácter de sus ocupaciones y el exceso frecuente de su labor intelectual. Si comparamos, digo, estos dos tipos, descubriremos seguramente la decadencia de las formas del segundo. El primero, transparentando en todo el cuerpo la salud y la belleza que lo animan, mostrará ancha la espalda, amplio el tórax, con hermosos relieves musculares. Lucirá un abdomen reducido y firme que al exhibir como en los vientres griegos una envoltura muscular parce demostrarnos el bienestar y potencia de las vísceras que esa envoltura sostiene y estimula. Miraremos el dorso erguido, los miembros flexibles, elegantes, con modelados precisos y correctos y la piel mostrando el bello tinte que el sol y el aire ponen en los cuerpos que continuamente besan.

El segundo poseerá, desde luego, un torax de menor capacidad. Hallaremos en él - como generalmente ocurre al médico que reconoce el oficinista sedentario - un cuello delgado, de laringe prominente, con músculos disminuidos, a veces, a su expresión más simple y a menudo velados por el tejido grasoso que, si no es escaso, suele ser excesivo, por especiales disposiciones dando al cuello el aspecto de los gruesos cuellos proconsulares, así llamados en recuerdo de los obesos procónsules romanos. El plano muscular dorsal, atrófico por el desuso que la vida inactiva le somete, facilitará el redondeamiento del dorso, que la gravedad provoca, dando a cuerpo esa actitud pasiva y cansada de flexión. El abdomen flácido y colgante o hipertenso y prominente será la región más notablemente deformada, indicando con eso el crónico malestar de las vísceras que encierra. Los miembros, por último, y especialmente los superiores, habrán perdido sus relieves musculares y aparecerán ya adiposos, ya escuálidos.

De estos dos sujetos, solo el primero es normal y solo el primero, por consiguiente, guardará sus atributos de belleza plástica. Su perfección anatómica es trasunto de su perfección funcional. Su sistema muscular, normalmente desarrollado, no ha de prevalecer, sin embargo, sobre los otros aparatos y sistemas.

El segundo, con toda la serie de modificaciones anatómicas evidenciadas por su decadencia morfológica, aunque sea el tipo dominante, aunque sus características pesen sobremanera en la determinación del hombre medio de los pueblos civilizados, no puede ni debe ser considerado como hombre normal, por el contrario, más bien merece ser ubicado en pleno campo patológico. De aquí pues que la determinación del canon humano basado en estadísticas hechas en pueblos civilizados actuales, no deba satisfacernos. 
El doctor Heckel, opone al hombre medio, el concepto de atleta, llamando así, no a un super-hombre muscular como parece creerse, sino al hombre normal, a aquel tipo en que todos los aparatos y todas las funciones guarden justo equilibrio, sin significar absolutamente predominio del sistema muscular ni aptitudes físicas excepcionales. También el concepto de Hipócrates era semejante. Y este tipo normal, de funciones correctas y exterior armonioso, corresponde, en general, al primitivo de vida libre en la naturaleza, al buen deportista actual y sigue muy de cerca a los tipos, acaso idealizados en las obras maestras de la estatuaria helena. En suma, refleja al hombre sano, al hombre fuerte. En sus más altas actitudes físicas y en el apogeo de sus valores plásticos.

Ahora bien, esto ha inducido a algunos a buscar en los cánones artísticos verdadero etalón de la raza humana. En este campo, la época clásica griega nos atrae con destellos de perpetua aurora. Las obras de los grandes maestros de los siglos quinto, cuarto y tercero A de C. no han sido aún sobrepasadas. Sin embargo, tampoco pisamos así un terreno firme, porque, desde luego, no es científico y, en seguida, porque el criterio artístico suele variar según los pueblos, las tendencias y las épocas. En la Grecia misma, considerando en la segunda mitad del siglo quinto A. de C. el Doríforo de Polieleto, como el tipo perfecto del hombre joven, destinado a servir de modelo definitivo, modificáronse posteriormente los cánones, sucediendo formas más esbeltas y finas a las majestuosas y fornidas del principio. Bástenos comparar las proporciones del Doríforo con obras maestras posteriores como la Diana de Leocares o el Apoxiomenos de Lisipo.

Los egipcios, por su parte, tenían su canon propio basado en la longitud del dedo medio que debería encontrarse contenido diecinueve veces en la altura del cuerpo (Charles Blane). Los romanos aceptaban los principios formulados por Vitruvio que más tarde, durante el renacimiento, fueron modificados por Leonardo de Vinci. Posteriormente, muchos son los autores que se han ocupado de cánones artísticos y proporciones (Lomazzo, Cousin, Gerdy, Durero, Rubens y, últimamente, Richer y Stratz, entre otros) sin que sus opiniones suelan coincidir.

Por otra parte, el concepto de Belleza es tan variable, que artistas célebres como el mismo Rubens, parecen complacerse en mostrarnos figuras pletóricas, obesas, de mejillas, esféricas y rojas. El tiziano en "La Flora" y Guido Reni en "Cleopatra" nos muestran tipos de verdaderas obesas, dicho sea sin dejar de inclinarnos ante los méritos de los célebres maestros. Otros, parecen ensalzar en sus obras la decadencia de la forma sedentaria y nos exhiben el cuello de cisne, los hombros caídos, el abdomen abultado y la atrofia muscular como en "El Nacimiento de venus", de Boticelli. Otros, han fijado en el mármol la deformación del talle por el corset, como ocurre en la "Diane" de Léveque, la "Danse", de Falguière, "Nimphe", de Octobre. Y en nuestro museo, si analizamos "La Perla del Mercader", de Valenzuela Puelma, o la "Casta Susana", de Guido Reni, apreciaremos fácilmente atrofia muscular generalizada, junto con cierto grado de adiposis muy común en la sedentaria moderna.

Ahora bien, después de eso, cabe preguntarse si se trata en realidad de una repercusión en el arte de la desviación de la forma del sedentarismo moderno o si el artista, en las obras citadas, solo ha tratado de impresionar provocando la emoción estética sin cuidarse de agradar, ya que el arte puede utilizar lo feo, que siempre emocione, puesto que lo bello comprende "todos los valores emocionadores, todas las cualidades susceptibles de ejercer 
en nosotros atracción o repulsión". Yo, al menos, me inclino por lo primero. No creo que en los trabajos nombrados, sus autores hayan pretendido emocionar con valores repulsivos, como efectivamente ocurre en el "Gregorio de Bottero", de Zuloaga, que nos muestra un cretino, $u$ otros famosos cuadros de figuras feas cuyos caracteres son bien diversos de los de las obras que consideramos. Pienso que, contrariamente, se manifiesta con nitidez en tales obras la intención de provocar la más pura y grata emoción estética, a pesar de las fallas señaladas. Lo que hay es que el artista, copiando del natural y teniendo por lo general ante su vista solo al tipo medio del sedentario, hombre o mujer, va perdiendo inconscientemente el concepto justo de la forma normal. Y así se explica, por ejemplo, que los artistas que produjeron "La Danse" y "Ninphe", en una época en que los efectos del corset llegaban al máximun, después de siglos de continuo uso, hayan copiado simplemente las deformaciones que veían sin reparar en que, visto al desnudo, ese tórax descarnado y estrechado en su base, violentando y alterando las vísceras, difícilmente dará una sensación de belleza perdurable. No podía ocurrir lo mismo entre los griegos que, entrenados desde niños en la práctica del ejercicio y habituados a mirar sus hermosos cuerpos desnudos en gimnasios y piscinas, habían adquirido un conocimiento exacto del exterior humano normal y bello.

Por otra parte, el vulgo mantiene conceptos viciados al respecto; ¿No suele considerarse al pletórico ventrudo, de redondos carrillos, como el prototipo de salud y aún de belleza física, diciéndose de él que "vende salud", que tiene "Buena planta"? Y sin embargo, se trata seguramente del gordo hipertenso, con tendencia a la esclerosis de sus tejidos vasculares. ¿No se repite a las señoras obesas que "gordura es parte de la hermosura"? Y, en verdad, lo que llamamos simple gordura es ya el comienzo de un, estado anormal manifestado, desde luego por esa ruptura del equilibrio adiposo muscular. Créese también corrientemente que en las formas femeninas calificadas de hermosas no deben diseñarse, ni levemente siquiera relieves osteomusculares, y solo se estima bello el escote parejo, relleno de grasa, en donde los músculos, huesos y tendones de la región se pierden en el tejido célulo-grasoso. Así, en el teatro, con tal criterio, suele preferirse la figura adiposa de la soprano o la contralto al cuerpo ágil, esbelto y musculoso de la bailarina.

Después de todo lo dicho sobre la variabilidad del concepto de belleza plástica, se deduce que es muy difícil encontrar cánones de belleza plásticos absolutos.

Sin embargo, no olvidemos que las obras de estética más pura, la más grandemente emocionadoras, son las que nos evidencian los tipos humanos más sanos y más fuertes, llegaron a identificarse, exteriormente, con el etalón, el pure-sang de la especie. Y así las Dianas y la Venus, los Apolos y los Discóbolos parecen irradiar de sus magníficas formas todo un tesoro de vigor y bienestar orgánico.

Por el contrario, tengamos presente que mientras más se aparta el individuo del tipo fundamental de su grupo, más o menos simbolizados en los cánones artísticos, más se aleja del estado de salud y, como el sedentarismo moderno, se aproxima y penetra en el dominio mismo de lo patológico.

Así, como para el perro no hay nada tan hermoso como el perro, y para la paloma, nada tan hermoso como la paloma, tentado estoy de decir que para los ojos del hombre es la figura humana la que puede llegar a la expresión de una mayor belleza, que al ser completa, ha de reflejar - lo repito - un optimun de valores biológicos humanos. 
Ahora bien, es en pos de ese optimum de valores biológicos que avanza la educación física sostenida en otras ciencias, como la antropología, la fisiología experimental, y la eugenesia, especialmente.

He querido llamar la atención hacia las relaciones de la salud con la belleza plástica para considerar la educación física en un aspecto, hasta cierto punto, nuevo y de primordial interés, ya que es evidente que la hermosura morfológica va a parejas con el perfeccionamiento funcional del individuo, constituyendo como un síntoma, como una demostración de este, y vice versa.

En artículos posteriores consideraré, en rasgos generales, se entiende, los factores generadores de forma que actúan sobre el individuo y el papel que, entre ellos, puede corresponder al ejercicio.

Pero quiero hacer notar, desde ahora, que lo que al respecto ignoramos, es mucho. La educación física misma, ahogada en empirismo, apenas si hoy levanta un poco la cabeza para vislumbrar a lo lejos el luminoso horizonte que conocerá un día. Científicamente se encuentra solo en los primeros balbuceos. Casi nada sabemos, a pesar de todo lo que, mientras más se ignora, más pomposamente se escribe. Y si un día se establecen las reglas precisas de una verdadera antropotecnia, habremos de luchar, por mucho tiempo todavía, con un gran factor negativo, buscado por el hombre mismo, que, intempestivamente, después de un largo período de ardua labor mejorada puede, en gran parte, retrotraernos a las fallas y taras del ancestro. Me refiero a la guerra, fuerza ciega que privando a la raza, en plena y briosa juventud, de la flor y nata de sus elementos - tanto físicos como intelectuales - solo deja para perpetuar la especie, simiente de segunda e ínfima categoría, aparte todavía del golpe asestado a esa multitud infantil que ha de crecer hambrienta y psíquicamente dañada por la hecatombe. Hablo de hechos segura y fatalmente comprobados con posterioridad a 1914.

Espero demostrar, no obstante, que a pesar de todos los tropiezos, de todas las ignorancias, de todos los delitos, existe la posibilidad de lograr, con los medios actuales, un mejoramiento de nuestro tipo, y que así como el artista cincelando el mármol afanoso, liberta al fin el tesoro de armonía que guardaba, así también el médico, la madre y el maestro, modelando con cariño el pequeño trozo de materia humana, libertarán al fin en él ese tesoro de bellezas plásticas y funcionales de cada niño, bajo apariencia a veces engañosa, puede, en germen, esconder en él. 


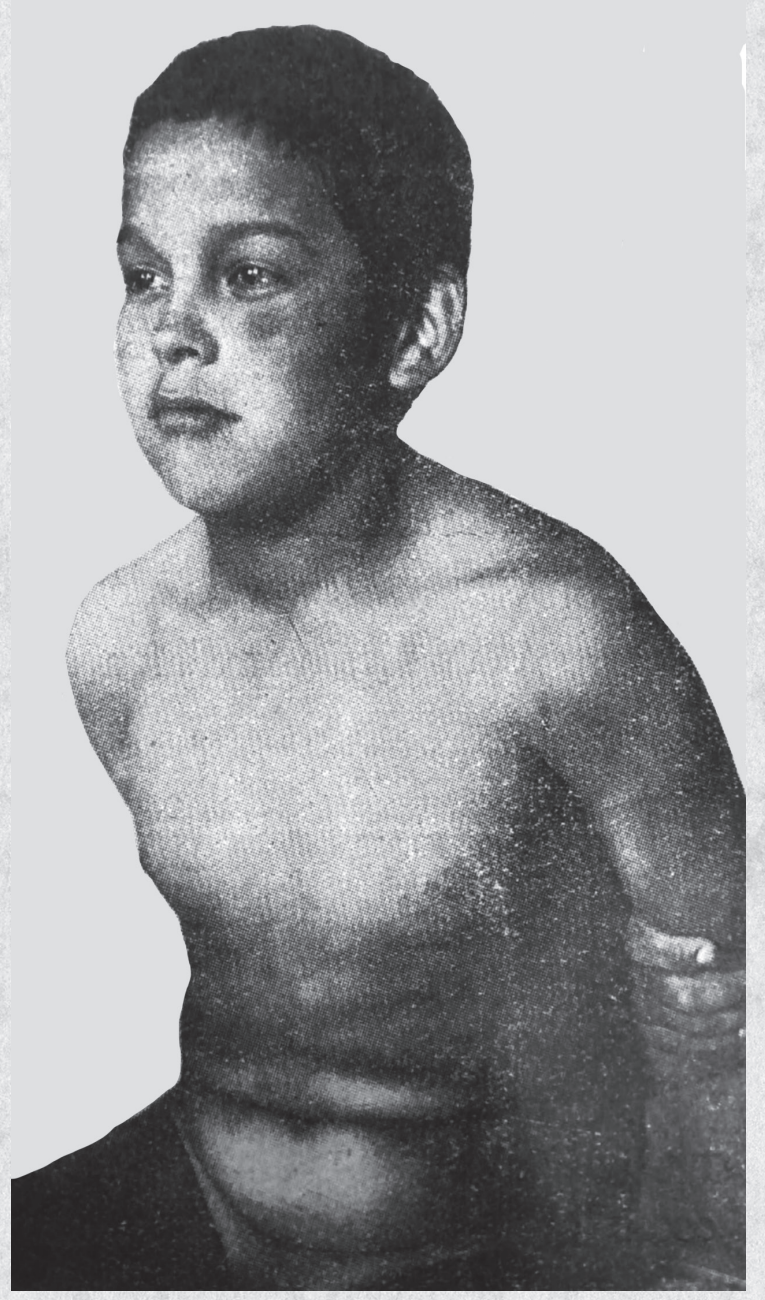

Figura 2: Niño enfermo crónico incurable. Nótese la posición más bien pasiva, a pesar del requerimiento de posar para el lente. La disminución del panículo adiposo y la emaciación de las masas musculares acentúan los relieves esqueléticos (esternón, costillas, clavícula, omóplato, cabeza humeral). Tiene la misma edad del anterior; pero su expresión es seria, grave. No sufre de dolores físicos agudos, pero el malestar íntimo de sus tejidos impregna el rostro de amargura. La mirada es muy triste y algo dura, como si intentase rebelarse contra su destino y como si presintiese el irremediable fin que se aproxima.

Fuente: BISQUERTT SUSARTE, Luis. Aspectos de la educación física. Revista de Educación, año 2, n.22, p.664. oct. 1930.
Figura 1: Niño Sano. Nótese la posición activa al percatarse de que se le retrata. La forma externa es normal y su rostro revela, nítidamente, el bienestar interno que resulta de la feliz concordancia de las cenestesis orgánicas. La expresión es risueña; la mirada es viva, alegre, traviesa.

Fuente: BISQUERTT SUSARTE, Luis. Aspectos de la educación física. Revista de Educación, año 2, n.22, p.664. oct. 1930.

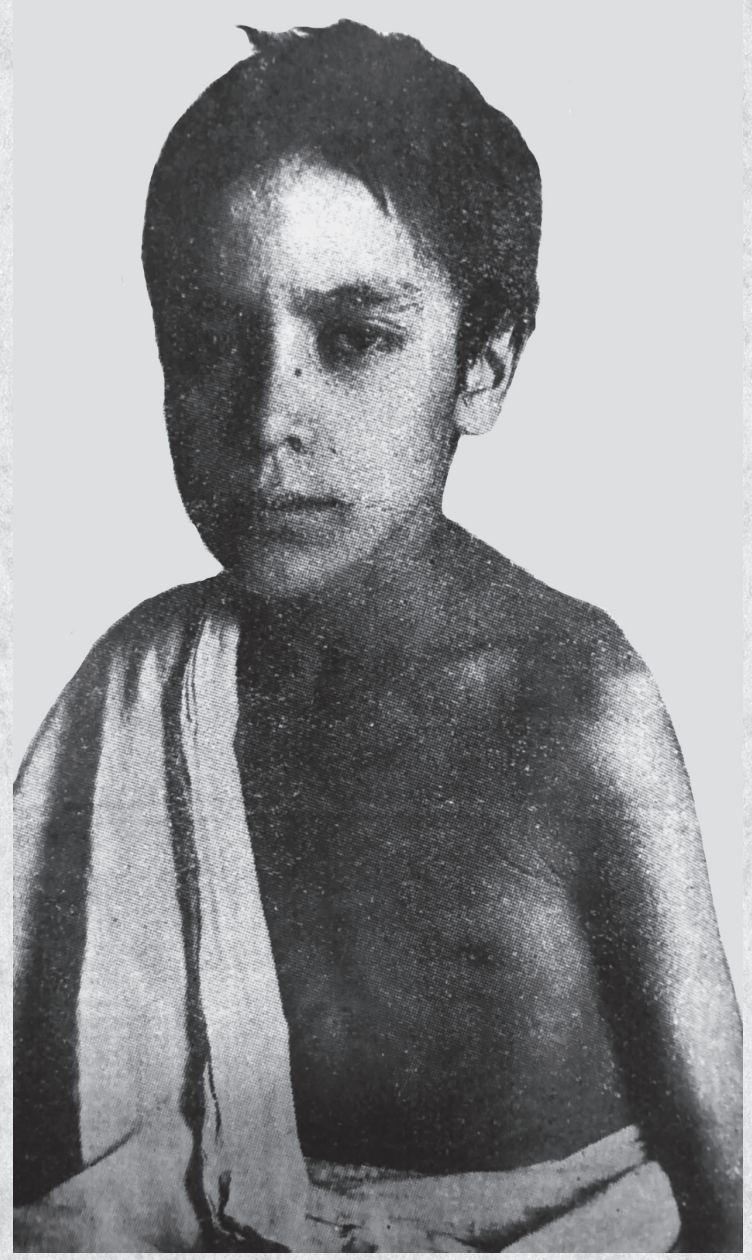




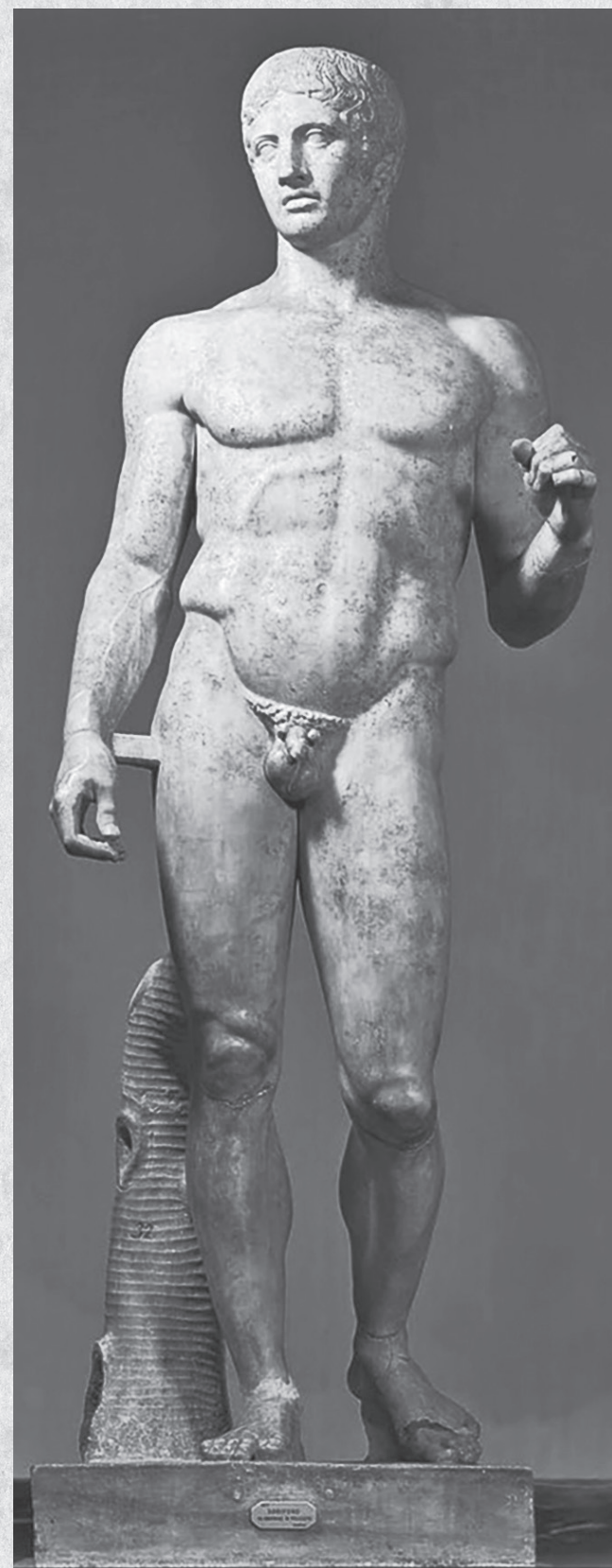

Figura 4: El Apoxyomenos. Escuela de Lisipo. De una época posterior al Doríforo y de formas más esbeltas que aquél, establece un nuevo cánon, demostrando que el criterio artístico, o acaso la morfología misma no eran ya idénticos en el siglo IV a.C. El torso, manteniendo siempre una hermosa musculatura, que se manifiesta en ese vigoroso modelado de la porción carnosa del oblicuo mayor, ha perdido algo de su importancia. Las extremidades inferiores son más altas que el músculo general, evidencia más el tipo largo que el del Doríforo.

Fuente: https://commons.wikimedia.org/wiki/File:Apoxyomenos_PioClementino_Inv1185.jpg
Figura 3: El Doríforo. He aquí un pure-sang humano, producto de la Grecia Clásica. El Doríforo fue el ideal griego de la figura humana durante el siglo $\mathrm{V}$ a.C. El torso de una belleza absoluta, nos muestra una envoltura muscular perfecta. Los pectorales, fuertes y bien delimitados, se asientan sobre un tórax amplio y levantado sin esfuerzo. Los trapecios y deltoides, bien desarrollados, marcan un vigoroso arranque de brazo, que en el sedentario moderno cuelgan del tronco como un péndulo. Los rectos anteriores del abdomen, que se adivinan firmes y elásticos, muestran sus intersecciones aponeuróticas, diseñando netamente sus porciones carnosas y dan la impresión de prestar un sólido apoyo a las vísceras abdominales. Los oblicuos dibujan por sobre las crestas iliacas esos hermosos relieves, tan difíciles de hallar hoy, aun en los mejores atletas, y que demuestran la gran potencia abdominal que debieron tener los atletas helenos.

Fuente: https://www.flickr.com/photos/8449304@N04/8213958936

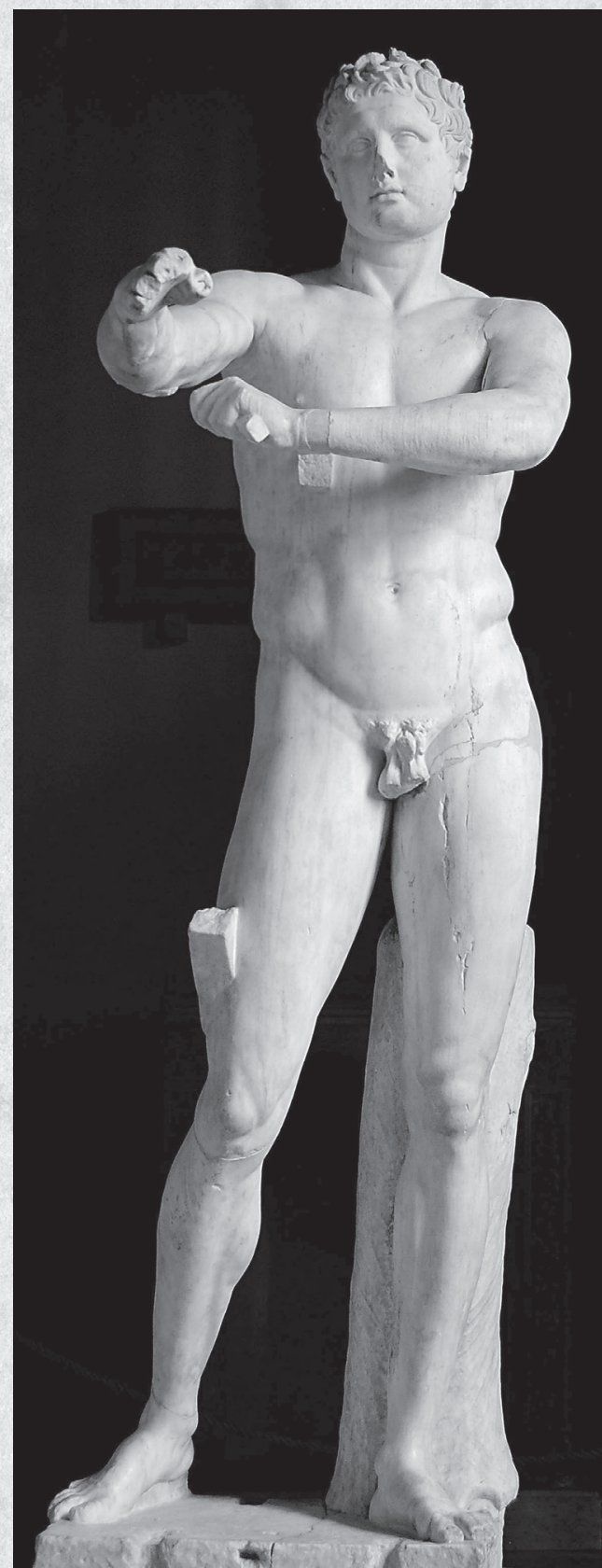




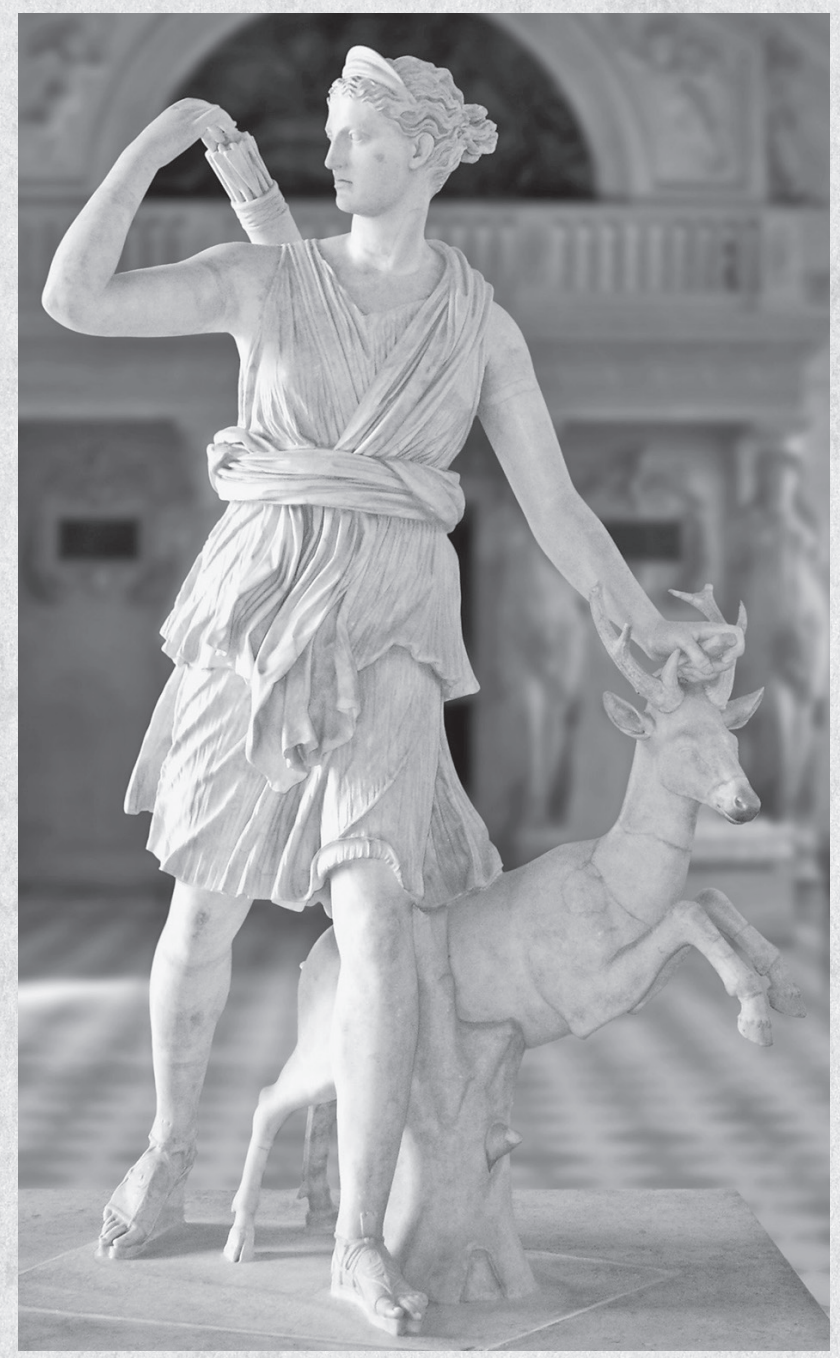

Figura 5: Diana y el Cervatillo. Escuela de Scopas. Vemos aquí una figura ágil, elegante, de senos robustos y firmes y de proporciones aún más esbeltas que las del Apoxiyómenos.

Fuente: https://es.wikipedia.org/wiki/Diana_de_Versalles\#/media/ File:Diane_de_Versailles_Leochares_2.jpg

Figura 6: Venus de Cnido. Escuela de Prasiletes. Llama la atención, en primer término, la majestuosa belleza del pecho y del abdomen. Los senos del tamaño justo, casi esféricos, turgentes y con el pezón al centro, se asientan sobre el pectoral mayor. No aparecen, como en la sedentaria moderna, decendidos y flácidos, pendientes de una superficie casi vertical. En el vientre, bajo la suavidad que da el desarrollo discreto del celular subcutáneo, se bosqueja un plano muscular potente que sólo una feliz constitución hereditaria y una vida activa muscular pueden dar.

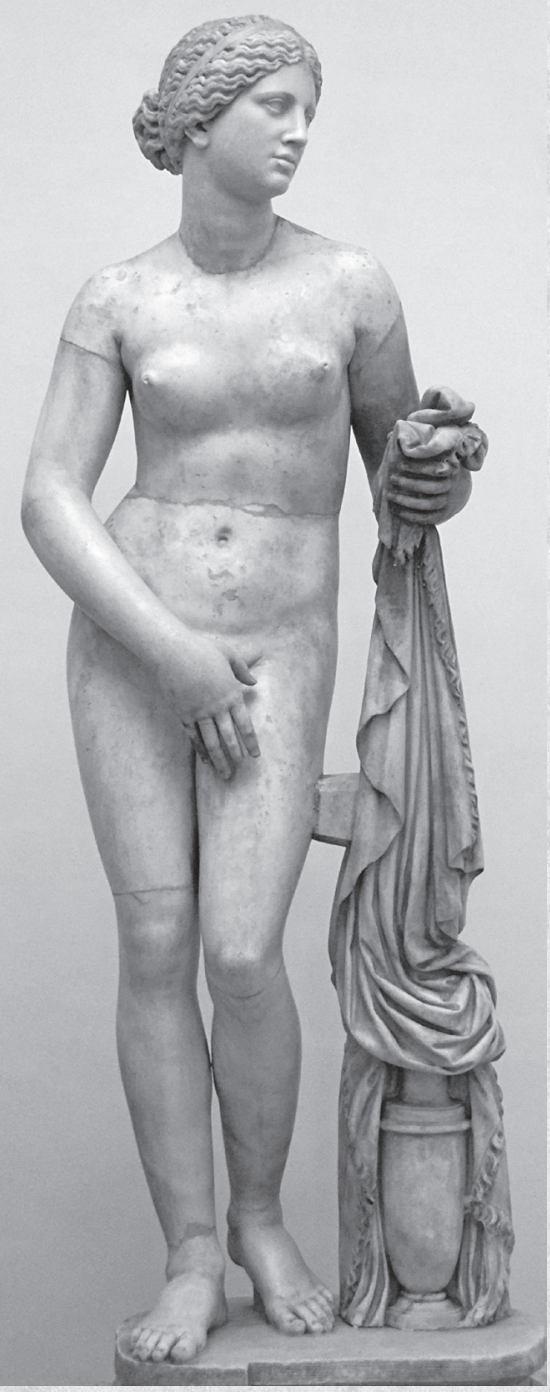




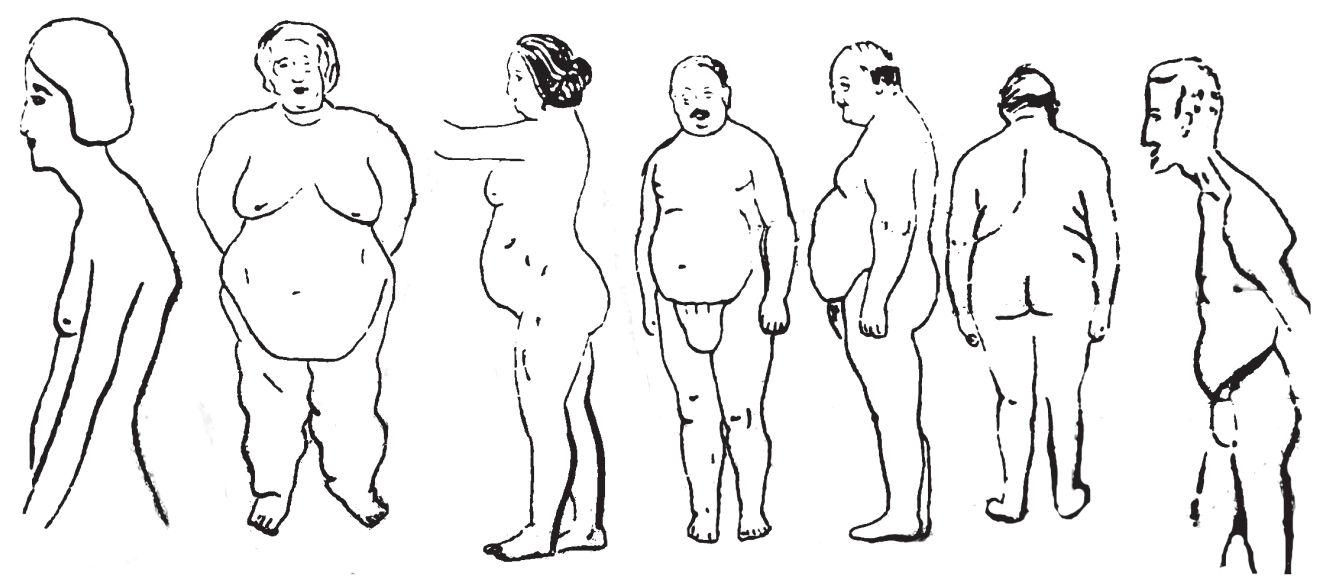

Figura 7: Sedentarios modernos según el autor. Nótese la sobrecarga adiposa en unos, la desnutrición en otros. Véase los vientres abultados, lisos, tensos, en algunos y los flácidos y colgantes en otros. Puede apreciarse, además, el dorso redondo, los senos descendidos e hipotónicos, el tórax plano, el cuello proconsular y su contrario llamado cuello de cisne. Compárese esta morfología, verdaderamente patológica, con la forma sana de las estatuas clásicas.

Fuente: BISQUERTT SUSARTE, Luis. Aspectos de la educación física. Revista de Educación, año 2, n.22, p.670. oct. 1930.

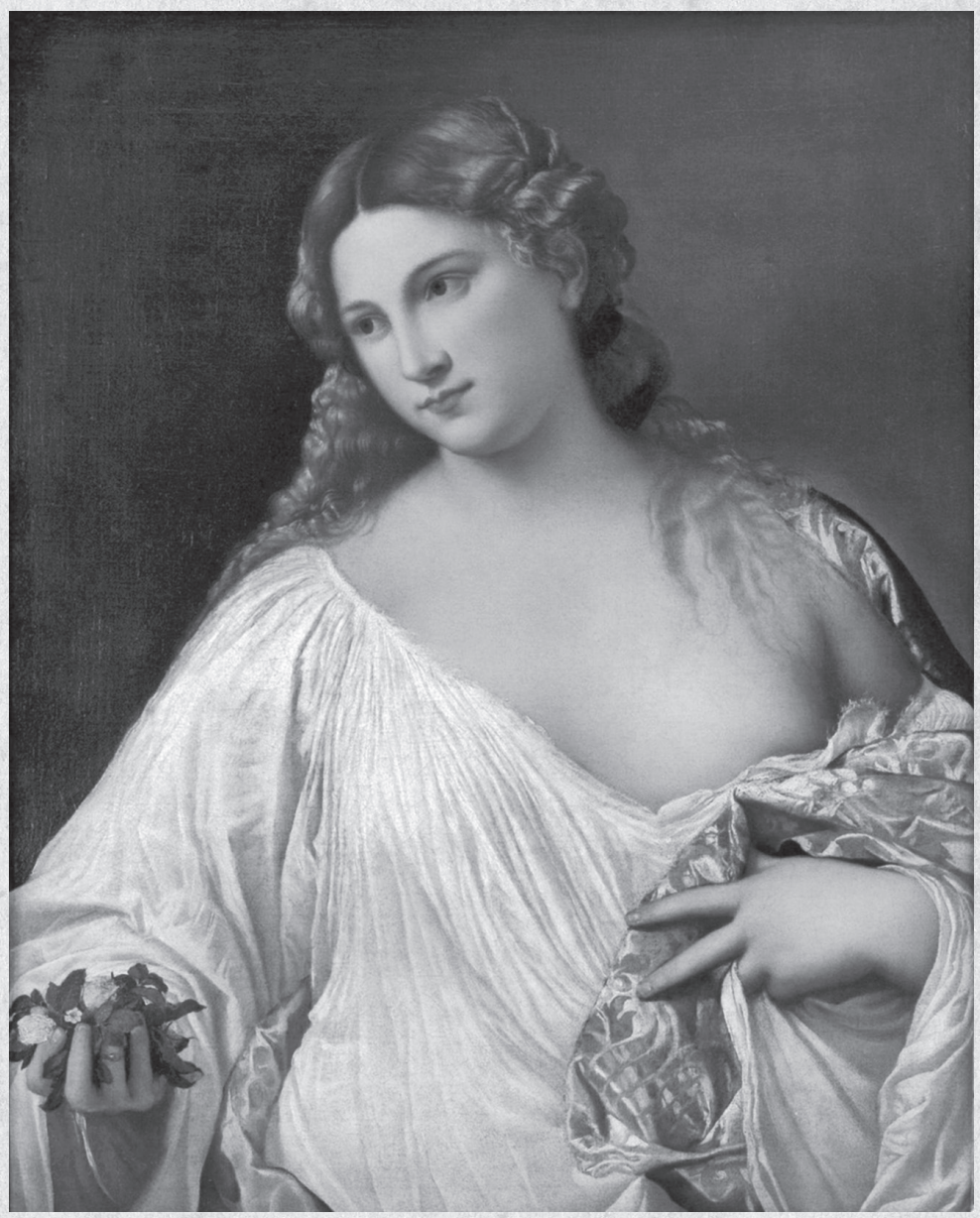

Figura 8: La Cleopatra. Fuido Reni. Nótese la adiposis generalizada que atenúa la belleza de la obra.

Fuente: https://commons.wikimedia. org/wiki/File:Guido_Reni_-Cleopatra_-_WGA19301.jpg 


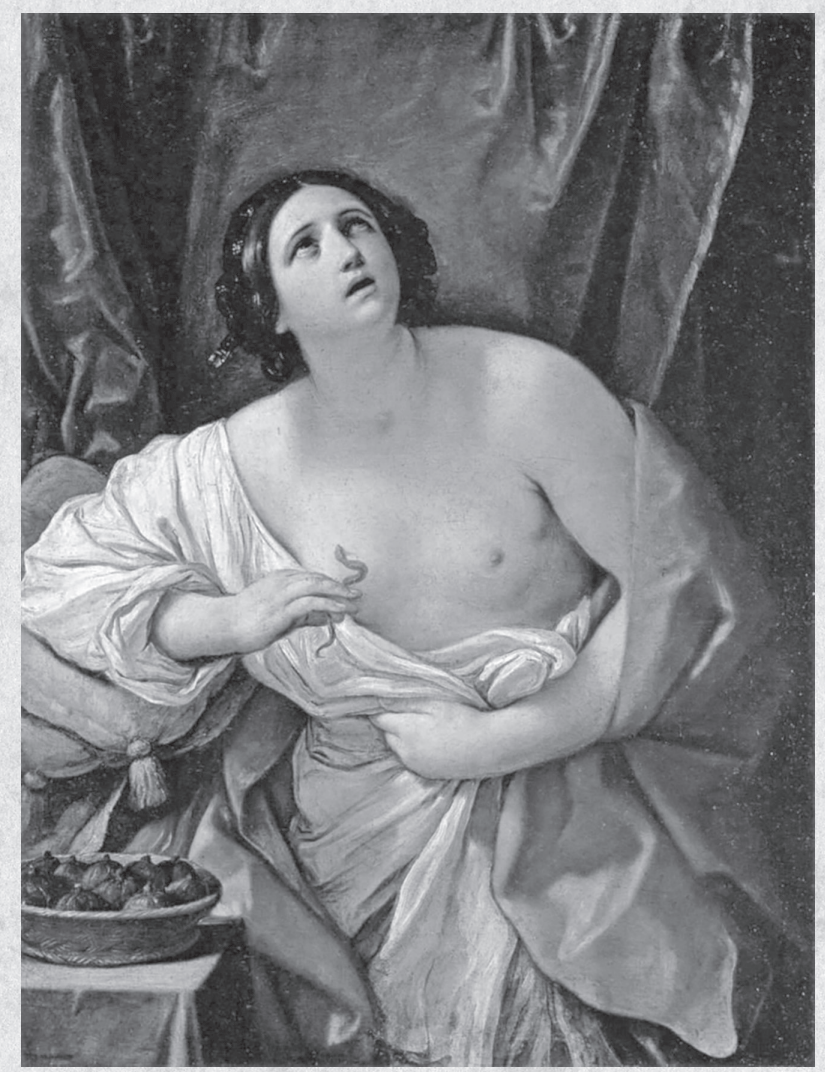

Figura 9: La Flora. Tiziaano. El cuello y pecho enteramente lisos, sin los relieves óseomusculares normales, nos indican sobrecarga grasosa y atrofia muscular.

Fuente: https://it.wikipedia.org/wiki/Flora_(Tiziano)

Figura 10: A Danse. Falguieri. Como en la Nymphe de Octobre, lo primero que llama la atención aquí, bajo el punto de vista que estamos considerando, es la deformación del talle por el corset. El tórax está estrechado en su base y aparece descarnado. El vientre está descendido y liso, el desarrollo muscular es, en general, pobre.

Fuente: https://www.pinterest.it/pin/561190803542657122/

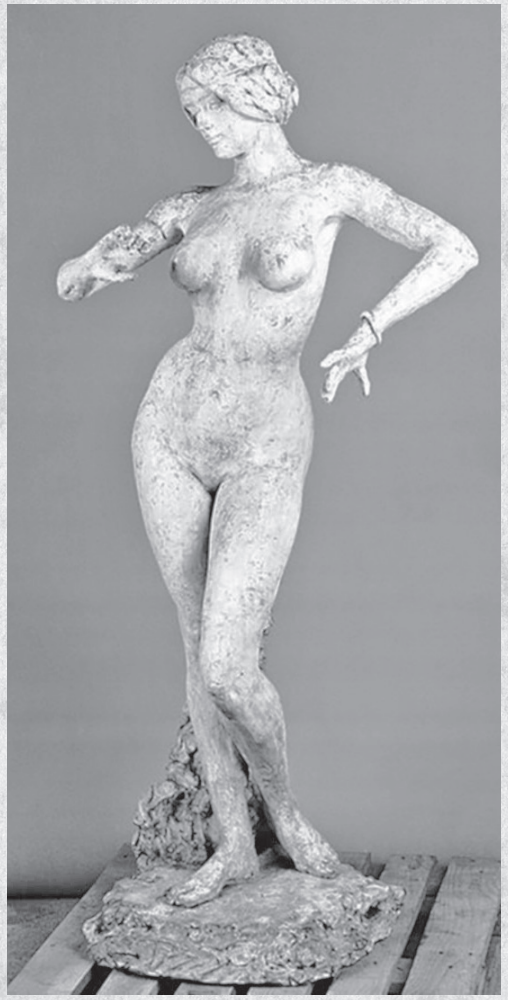

